Nontarget effects of orchard pesticides on natural enemies: Lessons from the field and laboratory

Elizabeth H. Beers ${ }^{\mathrm{a}}$, Nicholas J. Mills ${ }^{\mathrm{b}}$, Peter W. Shearer ${ }^{\mathrm{c}}$, David R. Horton ${ }^{\mathrm{d}}$, Eugene R. Milickzy $^{\mathrm{d}}$, Kaushalya G. Amarasekare ${ }^{\mathrm{e},}$ Lessando M. Gontijo ${ }^{\mathrm{f}}$

Running Head: Nontarget effects of orchard pesticides

${ }^{a}$ Department of Entomology, Tree Fruit Research and Extension Center, Washington State University, 1100 N. Western Ave., Wenatchee, WA 98801, USA. ebeers@wsu.edu

${ }^{\mathrm{b}}$ Department of Environmental Science and Policy Management, University of California, Berkeley, CA 94720-3114, USA. nmills@berkeley.edu

${ }^{c}$ Mid-Columbia Agricultural Research and Extension Center, Oregon State University, 3005 Experiment Station Drive, Hood River, OR 97031-9512, USA.'1 shearpw@ gmail.com

${ }^{d}$ USDA-ARS, Yakima Agricultural Research Laboratory, 5230 Konnowac Pass Road, Wapato, WA 98951, USA. david.horton@ ars.usda.gov

${ }^{\mathrm{e}}$ Mid-Columbia Agricultural Research and Extension Center, Oregon State University, 3005 Experiment Station Drive, Hood River, OR 97031-9512, USA. ${ }^{2}$ kamarase@tnstate.edu ${ }^{\mathrm{f}}$ Department of Entomology, Tree Fruit Research and Extension Center, Washington State University, 1100 N. Western Ave., Wenatchee, WA 98801, USA.³ lessandomg@gmail.com

\footnotetext{
${ }^{1} 1523$ Lincoln St. Unit 200, Hood River, OR 97031 USA

${ }^{2}$ Tennessee State University, Dept. of Agricultural and Environmental Sciences, Room 202 P, Farrell Westbrook Hall, 3500 John A Merritt Blvd,Nashville, TN 37209, USA

${ }^{3}$ Universidade Federal de Viçosa, Campus Florestal, Florestal, MG, Brasil 35690-000
} 
Corresponding author:

\section{Elizabeth Beers}

1100 N. Western Ave., Wenatchee, WA USA

Ph. 509-679-1010

ebeers@wsu.edu 


\section{Abstract}

The nontarget effects of insecticide programs used to control codling moth, Cydia pomonella Linnaeus (Lepidoptera: Tortricidae), were studied in large-plot field trials in apples, pears, and walnuts in the western United States. We assessed the health of the natural enemy community by sampling the abundance of natural enemies and by monitoring for outbreaks of secondary pests. The insecticides used in the field tests overlapped those tested in laboratory bioassays. Using these parallel lab and field studies, we examined two hypotheses: 1) pesticides found to have negative effects on natural enemy fitness in laboratory bioassays will predict reductions in natural enemy densities in the field, and 2) reductions in natural enemy densities in the field will result in outbreaks of secondary pests. We found only one clear instance, Forficula auricularia (Linnaeus) (Dermaptera: Forficulidae), where laboratory results documenting negative effects corresponded to a significant reduction in field studies (apple). This same instance was the only case where a reduction in a natural enemy population was associated with a significantly increased density of a secondary pest, Eriosoma lanigerum (Hausmann) (Hemiptera: Aphididae). There were several instances where secondary pest outbreaks were associated with unchanged or even increased natural enemy densities. The limited number of field trials, variability in field trial conditions among years and sites, duration of the negative effect relative to sampling interval, sampling efficiency, plot size/inter-plot movement, and compensation by other natural enemies attracted to a large host/prey resource may all have contributed to the poor predictive success. Overall, the laboratory bioassays predicted a far greater negative impact than was found in the field trials.

Keywords: nontarget effects, biological control, Tetranychidae, Aphididae, pear psylla 


\section{Introduction}

Decades of progress in developing and implementing more selective, sometimes speciesspecific controls for key/direct pests has left researchers with a new challenge: biological control of secondary pests (Blommers, 1992). Many of these pests are classed as induced pests, or ones whose natural enemies typically suppress them to low levels in the absence of pesticides. Most of the indirect pests (those feeding on plant tissues other than the marketable commodity) fall into this class; because of their feeding habits, higher densities of these pests are tolerated before an economic injury level is reached (Stern et al., 1959). This allows the latitude necessary for biological control to operate, with a zero-tolerance quarantine pest at the opposite end of the spectrum. The challenge then, becomes finding a suite of control tactics for key pests that will not disrupt control of secondary pests (Hoyt, 1969).

Laboratory bioassays of insecticides are arguably the most popular method of judging the potential impact on natural enemies and the efficacy of biological control. The coordinated testing program of the International Organization for Biological Control (IOBC) (Hassan, 1987; Hassan et al., 1991; Hassan et al., 1988; Sterk et al., 1999) represents the most comprehensive and sustained effort in this area. The IOBC tiered testing approach, where only those materials found harmful in laboratory studies are tested in semi-field and field tests, has provided a robust method for evaluating nontarget effects. Early screening efforts were relatively simple measurement of acute mortality, but over the years, laboratory methodology has grown increasingly sophisticated, including the use of multiple life stages, sublethal effects and population-level responses. The driving motivation behind these changes was to provide a more detailed and accurate picture of toxicological effects, which would in turn provide a better 
prediction of field effects (Bartlett, 1964; Croft, 1990; Desneux et al., 2007; Haynes, 1988; Stark and Banks, 2003; Stark et al., 2007; Wennergren and Stark, 2000).

Given the widespread use of laboratory bioassays for predicting field effects, relatively few studies have been devoted to assessing the accuracy of the predictions. Most of these studies refer to the IOBC rating system (Armenta et al., 2003; Raudonis et al., 2004; Rodrigues et al., 2002; Thomson and Hoffman, 2006; Tillman and Mulrooney, 2000). However, some authors promote a more experiential approach to understanding nontarget effects, using less detailed data taken directly from large-scale (spatial or temporal) field studies (Blommers, 1992; Pickett and McPhee, 1965). The latter approach is expensive, and thus difficult to sustain over long periods of time.

This paper is a case study comparing field studies (Beers et al., 2016, this issue and Shearer et al., 2016, this issue) with lab studies (Mills et al., 2016, this issue) that were designed in concert and conducted over a relatively short time period. Using these parallel lab and field studies, we examined two hypotheses: 1) pesticides found to have negative effects on natural enemy fitness in laboratory bioassays will predict reductions in natural enemy densities in the field, and 2) reductions in natural enemy densities in the field will result in outbreaks of secondary pests. We used a meta-analysis of the field results across multiple sites, years and crops to determine whether the population density of secondary pests or natural enemies increased, decreased, or were unchanged by pesticide applications, and the relative impact on vital rates from Mills et al. (2016, this issue) and published literature to assess the severity of pesticide effects in laboratory studies.

\section{Materials and methods}




\subsection{Laboratory bioassays}

A detailed description of the organisms tested, pesticides, and methodology for the laboratory studies are given in Mills et al. (2016, this issue), Amarasekare et al. (2016, this issue), and Amarasekare and Shearer (2013) and are briefly summarized here. Six arthropod species were tested using a life-table approach, with multiple bioassays testing different stages and responses in order to parameterize a stage-structured matrix model (PopTools, Hood (2010)). Two of the species tested (Aphelinus mali (Haldeman) (Hymenoptera: Aphelinidae) and Trioxys pallidus Haliday (Hymenoptera: Aphidiidae)) were sampled at the species level in the field trials; the other four species (Chrysoperla carnea (Neuroptera: Chrysopidae), Deraeocoris brevis (Uhler) (Heteroptera: Miridae), Hippodamia convergens Guérin-Méneville (Coleoptera: Coccinellidae), and Galendromus occidentalis (Nesbitt) (Acarina: Phytoseiidae)) were reported as part of a higher taxonomic group (predatory Neuroptera, predatory Heteroptera, Coccinellidae, and Phytoseiidae, respectively). Of the seven pesticides or pesticide mixtures tested in the laboratory, only five were used in one or more field trials, which varied among crops (Table 1).

\subsection{Field studies}

The field studies were conducted in three growing regions in the western U.S.: apples in central Washington, winter pears in the Hood River Valley of Oregon, and walnuts in the Sacramento Valley of California (see Shearer et al., 2016, this issue and Beers et al., 2016, this issue for a full description of methods). All study sites were in major production regions for their respective crops. The field studies were designed to test the potential disruptive effects of insecticides on secondary pests and their natural enemies, specifically those likely to be used 
against Cydia pomonella (L.) (Lepidoptera: Tortricidae). The treatments were similar among the crops, but were tailored to probable commercial use patterns in the respective crops. While the key pest, C. pomonella, was the same, the secondary pests studied varied by crop. In apple, the secondary pests sampled included aphids (woolly apple aphid, Eriosoma lanigerum (Hausmann) (Hemiptera: Aphididae); apple aphid, Aphis pomi De Geer (Hemiptera: Aphididae); and rosy apple aphid, Dysaphis plantaginea (Passerini) (Hemiptera: Aphididae)) and tetranychid mites (European red mite, Panonychus ulmi (Koch) (Acari: Tetranychidae) and twospotted spider mite, Tetranychus urticae Koch (Acari: Tetranychidae)). In the pear studies the only secondary pest of importance was pear psylla (Cacopsylla pyricola Förster (Hemiptera: Psyllidae)); although spider mites are pests of pear, the levels in our experiments were too low to merit reporting. In walnut, aphids (walnut aphid, Chromaphis juglandicola (Kaltenbach) (Hemiptera: Aphididae)) and tetranychid mites ( $P$. ulmi and $T$. urticae) were the most prevalent secondary pests.

Eleven field experiments were conducted from 2008-2011, using randomized complete block designs with 3-4 treatments. Each treatment was replicated 3-4 times in 0.27 to 0.61 ha plots. Depending on the year and the crop, the insecticide treatments were timed for the first or second generation of $C$. pomonella, or both (Beers et al., 2016, this issue and Shearer et al., 2016, this issue). There were 1-2 applications of the same material made against a given generation, and the application rates and volumes used reflected commercial practice in that crop. Materials used included chlorantraniliprole (Altacor 35WDG, DuPont, Wilmington, DE); cyantraniliprole (Exirel 0.83SE, DuPont, Wilmington, DE); spinetoram (Delegate 25WG, Dow AgroSciences, Indianapolis, IN); novaluron (Rimon 0.83EC, Chemtura, Middlebury, CT); methoxyfenozide (Intrepid 2F, Dow AgroSciences, Indianapolis, IN); lambda-cyhalothrin (Warrior II 2.08CS, Syngenta Crop Protection, Greensboro, NC); azinphosmethyl (Guthion 
50W, Bayer CropScience, Research Triangle Park, NC); lambda-cyhalothrin+chlorantraniliprole (Voliam Xpress, 0.417 and 0.835L, Syngenta Crop Protection; Greensboro, NC). All materials used in the field trials except methoxyfenozide, lambda-cyhalothrin+chlorantraniliprole (as a mixture), and azinphosmethyl were also screened in the laboratory bioassays.

\subsection{Data analysis}

\subsubsection{Data summary}

The taxa analyzed were either single species (e.g., C. pyricola, A. mali), beneficial members of a family (Coccinellidae and predatory Syrphidae [primarily Syrphinae]), members of higher taxonomic groups (parasitic Hymenoptera, predatory Heteroptera, predatory Neuroptera [specifically Chrysopidae and Hemerobiidae] and Araneae), or functional groups (pest, natural enemy) (Table 2). As an additional categorical variable, each natural enemy taxon was categorized as either 'mobile' (winged adult stage; potential for attraction to prey patches over longer distances) or 'resident' (those lacking the ability or propensity to fly). The rationale for this grouping is the hypothesis that resident natural enemies are more likely to be impacted by a disruptive treatment, while mobile natural enemies can re-invade the orchard from surrounding habitat after residues have declined. The mobile class included the parasitic Hymenoptera, predatory Heteroptera, predatory Neuroptera, predatory Syrphidae, and Coccinellidae (Table 2). The resident natural enemies included Forficula auricularia (L.) (Dermaptera: Forficulidae), Phytoseiidae, and Araneae. F. auricularia is capable of flight but rarely does so (Crumb et al., 1941), and thus was included with the resident natural enemies. In addition to an analysis of the secondary pest and natural enemy taxa, the data were categorized more broadly as either a 'pest' or 'natural enemy' to examine the underlying hypothesis that disruptive treatments would cause 
an increase in pest densities, and a decrease in natural enemies. For those taxa that captured by multiple sampling methods (e.g., leaf sample, tap counts), the single method deemed most effective was chosen for analysis (Table 2). For purposes of analysis, the plant volatile (PV) traps were considered as a single sampling method regardless of lure, and the insect captures were summed over all lure types used in a given year. Three parasitoid species that are closely associated with the secondary pests sampled (A. mali, Trechnites sp., T. pallidus) were considered as separate taxa, and excluded from the more general class 'parasitic Hymenoptera' to avoid duplication, and possibly biasing the meta-analysis effect.

Cumulative insect-days (CIDs) (Ruppel, 1983) were calculated for each taxon from counts taken every 2-3 weeks throughout the season:

$$
\mathrm{CID}=\Sigma 0.5\left(P_{a}+P_{b}\right) D_{a-b}
$$

where $P_{a}$ is the population density (e.g., mean mites/leaf) at time $a, P_{b}$ is the population density at time $b$, and $D_{a-b}$ is the number of days between time $a$ and time $b$. Trap counts, because they represented the number of insects accumulated over the deployment period (as opposed to a single point in time like leaf or tap samples) were summed over the season to calculate the CID. In order to meet the assumption of normality, data were transformed $\log (x+1)$ before analysis.

\subsubsection{Meta-analysis}

Effect sizes were estimated in MetaWin 2.0 (Rosenberg et al., 1999) using Hedges' $d$ for each experimental treatment(s) compared with a control, using the means, standard deviation, and number of replicates of the CIDs for the various groups. The weighted mean effect size of a 
grouping variable was calculated using a categorical random-effects model. The mean effect size was declared significant if the $95 \%$ bootstrap confidence interval (999 iterations) did not include zero (Rosenberg et al., 1999). The grouping variables used included 1) taxon studied, 2) pest/natural enemy, and 3) mobile/resident natural enemy. In all analyses, average effect sizes with $<2$ observations were excluded from the analyses.

Most of the field studies did not include a true untreated control because of the danger of economic damage, so a least-harmful insecticide treatment was chosen as the basis for comparison to the other insecticide treatments. Chlorantraniliprole was used in all of the field experiments and was least harmful insecticide in laboratory experiments (Mills et al., 2016, this issue), thus it was chosen post-hoc as the control group for comparison to other treatments. Where chlorantraniliprole was compared to multiple treatments, the mean, standard deviation and $n$ replicates were first pooled using the method of Borenstein et al. (2009), for a total of $n=90$ observations. Pooling the non-chlorantraniliprole treatments was deemed necessary because they were quite variable among the crops and years, resulting in too few observations for some of the treatments to make meaningful comparisons. The exception was spinetoram (see Section 2.3.2.2.), which was used in the majority of the experiments ( $n=82)$. Thus, for most analyses, a positive mean effect size indicated higher densities in the other treatment(s) relative to the chlorantraniliprole treatment, and a negative mean effect size indicated lower densities. The exception to this was in the walnut experiments, where a true control was included in all experiments. This allowed a limited analysis of the effect of chlorantraniliprole versus an untreated control $(n=16)$. The analyses were grouped in two types: those that considered the data from a single crop, and those that used data from all three crops. 


\subsubsection{Crops analyzed separately}

For an initial summary of the data, the three crops were analyzed separately using taxon as the grouping variable (using data from multiple experiments or years). To make the results comparable among crops, the chlorantraniliprole treatment was used as the least disruptive treatment for natural enemies (control), and was compared to the other pesticides in the trial. An additional comparison of the true (untreated) control versus chlorantraniliprole was conducted in a separate analysis of the walnut dataset.

\subsubsection{Crops analyzed together}

In order to draw broader conclusions about disruptive effects, analyses were performed using data from all three crops. This first analysis compared chlorantraniliprole versus other insecticide treatments, using natural enemy taxa in common to two or more of the crops. The second analysis compared chlorantraniliprole to spinetoram only, the two most commonly used insecticides $(n=82)$, using all pests and natural enemies. The use of a single comparison treatment (spinetoram) helped reduce possible bias from variations in response due to multiple (pooled) treatments.

\subsubsection{Functional group analysis}

Finally, two analyses were performed using functional groups at the categorical variable. The first analysis compared insecticide effects on resident versus mobile natural enemies, and the second compared effects on pests versus natural enemies. In the latter case, both chlorantraniliprole versus other (pooled) insecticide treatments and chlorantraniliprole versus spinetoram were compared. 


\section{Results and Discussion}

\subsection{Crops analyzed separately}

\subsubsection{Apple pests and natural enemies}

Three of the apple pests (E. lanigerum, T. urticae, P. ulmi) showed significant positive effect sizes (Fig. 1A), indicating that compared to the chlorantraniliprole treatment, densities of these secondary pests were higher in other insecticide treatments across multiple field trials. While the increase in the pest populations suggested natural enemy disruption, in the case of $E$. lanigerum, higher densities in the other insecticide treatments cannot be explained by lower densities of either mobile generalist predators or the specialist parasitoid A. mali; in fact, the effect sizes for predatory Syrphidae and A. mali were positive rather than negative (Fig. 1A). The predatory syrphid effect size was drawn from PV-baited traps, and thus reflects densities of mobile adults rather than larvae, which may have been able to recolonize the plots and to be drawn to the traps before being affected by insecticide residues. It also seems likely that these generalist aphid predators were drawn to the large prey resource represented by high populations of E. lanigerum. The positive effect size for A. mali was not predicted by the laboratory bioassays, given that all of the other insecticide treatments were more toxic to A. mali than chlorantraniliprole (Gontijo \& Beers, unpublished; Mills et al., 2016, this issue). The same reasoning applies to this specialist parasitoid as it did to the predatory Syrphidae: response to a large host resource outweighed the toxic effects of the insecticides. However, unlike the predatory syrphids, A. mali is essentially host-specific, and is thus less likely to be recruited from outside the orchard, unless a neighboring orchard is also infested with E. lanigerum. The only strong negative effect on one of the predators of E. lanigerum was for $F$. auricularia, possibly 
indicating a more important role for this predator in Washington State than was previously assumed (Carroll et al., 1985); it has been considered an important predator of E. lanigerum in other regions (Ravensburg, 1981; Wearing et al., 2010). F. auricularia was not among the natural enemies tested in our laboratory bioassays, but previous laboratory tests (Unruh et al., 2006) indicated that novaluron and spinosad (a compound related to spinetoram), were both highly toxic to $F$. auricularia. Other workers have also noted deleterious effects of pesticides on forficulids, including spinosad (Cisneros et al., 2002) and diflubenzuron (Ravensburg, 1981; Sauphanor, 1993), a benzoylurea insect growth regulator related to novaluron.

The greater densities of the two tetranychid mites, P. ulmi and T. urticae, in the other insecticide treatments relative to chlorantraniliprole also appeared to be unrelated to disruption of their phytoseiid predators, given the lack of a significant effect size in the latter. While the laboratory bioassays determined a much higher level of toxicity to G. occidentalis for both lambda-cyhalothrin and spinetoram than for chlorantraniliprole, and consequently a potential for disruption of integrated mite control, this effect was not verified by our field studies in apples using seasonal population indices. The effects of the pesticides on G. occidentalis may have been sufficient to allow outbreaks of the tetranychid prey over the short term, but was obscured in the seasonal CID indices of densities.

\subsubsection{Pear pests and natural enemies}

Only one secondary pest of pear ( $C$. pyricola), was present in sufficient numbers to be recorded; the effect size for this pest was positive, but not significant (Fig. 1B). Among the natural enemies, the effect sizes for predatory Neuroptera and Araneae were positive and significant, indicating higher natural enemy densities in the other insecticide treatments 
(cyantraniliprole, spinetoram) compared to the chlorantraniliprole treatment. The positive effect on predatory Neuroptera was not predicted from the laboratory bioassays, where all insecticides (including chlorantraniliprole) were considered moderately harmful to harmful to $C$. carnea; nor could the increase be attributed to a significantly increased level of prey. However, the two diamide insecticides (chlorantraniliprole and cyantraniliprole) both caused negative growth rates for $C$. carnea in the laboratory bioassays (Mills et al., 2016, this issue) while one of the other insecticide treatments (spinetoram) did not. C. carnea had an exceptionally high $\mathrm{R}_{\mathrm{o}}$ among the natural enemies (Mills et al., 2016, this issue), and this high net reproductive rate coupled with immigration from surrounding habitat may have produced the positive effect size.

\subsubsection{Walnut pests and natural enemies}

The effect size for parasitic Hymenoptera was negative, indicating densities were lower in the other insecticide treatments relative to chlorantraniliprole. This broad taxonomic grouping provides some indication of ecosystem stress, but cannot be tied to suppression of any of the secondary pests studied. For example, the primary aphid pest of walnut, $C$. juglandicola, had a significant positive effect size in the other insecticide treatments compared to chlorantraniliprole (Fig. 1C), indicating those treatments (lambda-cyhalothrin, spinetoram) were potentially disruptive to biological control. The laboratory bioassays indicated a greater toxicity of lambdacyhalothrin and spinetoram than of chlorantraniliprole for the specialist parasitoid T. pallidus (Mills et al., 2016, this issue). However, the effect size for T. pallidus from the meta-analysis of adults collected from PV-baited traps was non-significant, possibly because the chlorantraniliprole treatment was also found to be harmful to this parasitoid. The same problem exists for the generalist predators (C. carnea, H. convergens), where the chlorantraniliprole 
treatment was only slightly less harmful than the other insecticide treatments (Mills et al., 2016, this issue).

The other insecticide treatments had a significant negative effect compared to chlorantraniliprole on the two species of tetranychid mites found in walnut. This was the reverse of the effect found in apple for the same tetranychid species, and again cannot be explained by a significant effect size for the phytoseiid predators in the meta-analysis of the walnut data. The other insecticide treatments are ranged from small to moderate acaricidal activity, but tend to be more toxic to phytoseiid mite predators than they are to their tetranychid prey (Beers and Schmidt, 2014 and Schmidt-Jeffris and Beers, unpublished).

\subsubsection{Control versus chlorantraniliprole (walnut)}

A comparison of the true (untreated) control group versus chlorantraniliprole in the walnut subset of the data (the former was excluded from the walnut analysis described above) revealed interesting trends in the secondary pest groups (Fig. 1D). The trend in the pest groups was just the opposite in this analysis in comparison to the analysis of chlorantraniliprole as the control treatment (Fig. 1C). Despite its designation as the least disruptive treatment in other crops (where a true control was lacking), there were significant positive effect sizes for the two tetranychid species. This positive effect was not explained either by an effect on phytoseiid predators in the meta-analysis, or by the laboratory bioassays. The effect size for $C$. juglandicola was negative, indicating lower populations in the chlorantraniliprole treatment than in the control. The effect size on its specialist parasitoid, T. pallidus, was positive although nonsignificant, as were the effect sizes for predatory Neuroptera, parasitic Hymenoptera and Phytoseiidae). Chlorantraniliprole was rated as moderately harmful to harmful in the laboratory 
bioassays for T. pallidus, C. carnea, and H. convergens (Mills et al., 2016, this issue), and thus we would have expected a negative effect size for one or more of these groups.

\subsection{Crops analyzed together}

\subsubsection{Natural enemies common across crops}

When those natural enemy taxa that were common to two or three of the crops studied were considered, only $F$. auricularia showed a significant negative effect size when comparing chlorantraniliprole to the other insecticide treatments (Fig. 2A). This reflects the strong negative effect from the apple studies, plus a negative (although non-significant) effect from the pear studies. Predatory Neuroptera were monitored in all three crops, with a positive effect size for all three crops individually and when analyzed together. This appears to be somewhat contradictory to the laboratory data, in that all the insecticides tested were considered harmful to C. carnea, and chlorantraniliprole, cyantraniliprole, and lambda-cyhalothrin produced negative values for $r$ (Mills et al., 2016, this issue).

\subsubsection{Chlorantraniliprole versus spinetoram, pests and natural enemies}

Of the secondary pest species recorded, only three had significantly positive effect size in

the spinetoram treatments (the same three as in the apple-only analysis); however, the strength of the effect from the apple studies outweighed the opposite effect in the walnut studies (Fig. 2B). Of the natural enemy taxa, the effect size of parasitic Hymenoptera was negative, which was fairly consistent across analyses that used chlorantraniliprole as the control. Positive effect sizes were also noted for predatory Neuroptera, predatory Syrphidae, and A. mali in the spinetoram treatments, while Trechnites sp., F. auricularia, and parasitic Hymenoptera had negative ones. 
The significant positive effect size for A. mali also occurred in the apple-only analysis. The trend for a positive effect size for predatory Neuroptera and predatory Syrphidae was common to all analyses, but only became statistically significant when all other insecticide treatments except spinetoram were omitted from the analysis. Similarly, the use of only one comparison insecticide (spinetoram) caused the negative effect on Trechnites sp. to become significant, while in the larger pear dataset, it was not.

\subsection{Functional group analysis}

\subsubsection{Mobile versus resident natural enemies}

The analysis of the mobile versus resident natural enemy groups comparing chlorantraniliprole to the other insecticide treatments (using all natural enemy taxa from all crops) failed to show significant effect sizes in either group (Fig. 3A). There was a trend for lower densities of resident natural enemies, and a corresponding trend for higher densities of mobile natural enemies in the other insecticide treatments relative to chlorantraniliprole. These groupings, while potentially ecologically meaningful, may be too broad to overcome differences in cropping systems, habitats, and sampling methods, and the effects of multiple species exposed to multiple pesticides. However, it was interesting to note that resident natural enemies appeared to be more affected (negative effect size) than mobile natural enemies, even though these trends were not significant.

\subsubsection{Pests versus natural enemies}

When secondary pests and natural enemies were considered as functional groups (comparing chlorantraniliprole to spinetoram only or to all other insecticide treatments, across all 
three crops), there was a significant positive effect size for the secondary pests, while the effect size for natural enemies was near zero and non-significant in both analyses (Fig. 3B). This result echoes to some extent other analyses: where they occurred, outbreaks of secondary pests were detectable with the sampling methods used, but results with natural enemies were more subtle and variable.

When we re-examined our results in light of the two original hypotheses, we found marginal support for either. For the first hypothesis (that pesticides found to have negative effects in the laboratory will cause reductions of natural enemies in the field), we found only one clear instance where that was true (F. auricularia; Figs. 1A, 2A). Laboratory data (in this case from the published literature (Unruh et al., 2006) documented a detrimental effect of novaluron on F. auricularia. Spinetoram, another pesticide used in the apple field studies, is closely related to spinosad, for which detrimental effects on F. auricularia have been (Cisneros et al., 2002; Unruh et al., 2006; Vogt et al., 2010). This lack of correspondence may have occurred in part because negative effects in the field studies were fairly uncommon, even though they were quite plentiful in the laboratory studies (Mills et al, 2016, this issue). There were two other instances in our analyses where natural enemies were significantly suppressed by the treatments (parasitic Hymemoptera, Figs. 1C, 2A) and Trechnites sp. (Fig. 2B), but the first class is too broad to make detailed comparisons, and there were no corresponding laboratory data for Trechnites sp.

For the second hypothesis (suppression of natural enemies will result in secondary pest outbreaks), the same instance (reduction of $F$. auricularia) is the only one associated with a high levels of one of the secondary pests studied (E. lanigerum).

The lack support for our original hypotheses led us to formulate the question in a slightly different manner: 'Did the laboratory bioassays predict the field results?' Out of 17 available 
comparisons between laboratory and field results (viz., natural enemy densities were increased, decreased, or unchanged), we found only 5 instances where the answer was 'yes', despite the more extensive laboratory test protocols used in many cases (Table 3). Three of those instances represent the case where no effect was predicted, and none occurred. We might conclude from this finding that 1) if no harmful effects are found in a laboratory bioassay, then none will occur in the field (this is the premise of the IOBC tiered testing approach); or 2) if all treatments are equally harmful (absent a control), then no differences will occur in field trials. In only two cases (F. auricularia and Hymenoptera) was a negative effect predicted (from other literature), and the effect was evident in the field trials. Interestingly, there were no 'false negatives' from our studies (viz., no effect predicted by laboratory bioassays (0), but a negative effect found in the field (-)). For the most part, the laboratory studies predicted a far more serious negative impact than was found in the field studies.

There are a number of factors which might have been responsible for the poor correspondence. The time scales of the two types of experiments varied considerably; laboratory measurements of natural enemies were made over the course of a few days or weeks; field counts were taken over the course of 4-5 months, and short-term suppression may not have been captured in the CIDs. Although designed to simulate population-level effects, the laboratory studies capture the effect of multiple applications, the duration of the residual effect, or immigration from outside the treated area. There is no accepted standard for appropriate plot size in studies of this type (Macfadyen et al., 2014), but larger is generally considered more appropriate when studying highly mobile natural enemies to minimize the effect of inter-plot movement. The absence of a true control is also problematic for determining the effects of pesticides, but is a common feature of large-scale studies in commercial fields. On the pest 
resurgence side of the equation, the insecticides used may have exerted partial or substantial pest control; thus, even if biological control was disrupted, no pest outbreak resulted.

Despite these difficulties, laboratory bioassays, especially those that simulate populationlevel effects, are useful in the process of developing integrated pest management programs, in that they flag those materials that are more likely to produce negative effects in the field. This can warn pest control consultants to be alert for pest problems. In general, pesticides shown to be less harmful in laboratory studies (in our tests, chlorantraniliprole) were less harmful in the field if we use pest outbreaks as our metric. Those that had more severe effects over a greater number of natural enemy taxa were more frequently associated with pest outbreaks. This "pest-centric" association was much clearer than the causal association with natural enemy suppression, thus pest outbreaks are arguably a simpler and more straightforward measure of nontarget effects. 


\section{Acknowledgements}

The authors gratefully acknowledge the technical help of Peter Smytheman and Bruce Greenfield, as well as undergraduates Allie Bock, Alix Crilly, Kaitlin Parsons, Natasza Lorentz, Kylie Martin, Alyssa White, Denise Burnett, Mattie Warner and David Gutierrez in pest and natural enemy sampling. We thank Chris Sater for assistance in proofreading and graphics

preparation. These experiments were funded in part by USDA Specialty Crop Research Initiative Proposal Number 2008-04854 and the Washington Tree Fruit Research Commission. 


\section{References}

Amarasekare, K.G., Shearer, P.W., 2013. Laboratory bioassays to estimate the lethal and sublethal effects of various insecticides and fungicides on Deraeocoris brevis (Hemiptera: Miridae). J. Econ. Entomol. 106, 776-785.

Amarasekare, K.G., Shearer, P.W., Mills, N.J., 2016. Testing the selectivity of pesticide effects on natural enemies in laboratory bioassays. Biol. Control (this issue).

Armenta, R., Martinez, M., Chapman, J.W., Magallanes, R., Goulson, D., Caballero, P., Cave, R.D., Cisneros, J., Valle, J., Castillejos, V., Penangos, D.I., Garcia, L.F., Williams, T., 2003. Impact of a nucleopolyhedrovirus bioinsecticide and selected synthetic insecticides on the abundance of insect natural enemies on maize in southern Mexico. J. Econ. Entomol. 96, 649-661.

Bartlett, B.R., 1964. Toxicity of some pesticides to eggs, larvae and adults of the green lacewing, Chrysopa carnea. J. Econ. Entomol. 57, 366-369.

Beers, E.H., Horton, D.R., Miliczky, E.R., 2016a. Pesticides used against Cydia pomonella disrupt biological control of secondary pests of apple. Biol. Control (this issue).

Beers, E.H., Horton, D.R., Miliczky, E.R., 2016b. Pesticides used for codling moth (Lepidoptera: Tortricidae) disrupt biological control of secondary pests of apple. Biol. Control (this issue).

Beers, E.H., Schmidt, R.A., 2014. Impacts of orchard pesticides on Galendromus occidentalis: Lethal and sublethal effects. Crop Prot. 56, 16-24.

Blommers, L., 1992. Selective package and natural control in orchard IPM. Acta Phytopathol. Entomol. Hung 27, 127-134. 
Borenstein, M., Hedges, L.V., Higgins, J.P.T., Rothstein, H.R., 2009. Independent subgroups within a study. Chap. 23., Introduction to Meta-Analysis. John Wiley \& Sons, Chichester, UK, pp. 217-223.

Carroll, D.P., Walker, J.T.S., Hoyt, S.C., 1985. European earwigs (Dermaptera: Forficulidae) fail to control apple aphids on bearing apple trees and woolly apple aphids (Homoptera: Aphididae) in apple rootstock stool beds. J. Econ. Entomol. 78, 972-974.

Cisneros, J., Goulson, D., Derwent, L.C., Penagos, D.I., Hernandez, O., Williams, T., 2002. Toxic effects of spinosad on predatory insects. Biol. Control 23, 156-163.

Croft, B.A., 1990. Arthropod biological control agents and pesticides. John Wiley \& Sons, New York, NY.

Crumb, S.E., Eide, P.M., Bonn, A.E., 1941. The European earwig. USDA Technical Bulletin 766, pp. $1-76$.

Desneux, N., Decourtye, A., Delpuech, J.-M., 2007. Sublethal effects of pesticides on beneficial arthropods. Annu. Rev. Entomol. 52, 81-106.

Hassan, S., 1987. Results of the third joint pesticide testing programme by the IOBC/WPRSworking group 'pesticides and beneficial organisms'. J. Appl. Entomol. 103, 92-107.

Hassan, S.A., Bigler, F., Bogenshutz, H., Boller, E., Brun, J., Calis, J.N.M., Chiverton, P., Coremans-Pelseneer, J., Duso, C., Lewis, G.B., Mansour, F., Moreth, L., Oomen, P.A., Overmeer, W.P.J., Polgar, L., Rieckmann, W., Samsoe-Petersen, L., Staubli, A., Sterk, G., Tavares, K., Tuset, J.J., Viggiani, G., 1991. Results of the fifth joint pesticide testing programme carried out by the IOBC/WPRS- Working Group "Pesticides and Beneficial Organisms". Entomophaga 36, 55 - 67. 
Hassan, S.A., Bigler, F., Bogenshutz, H., Boller, E., Brun, J., Chiverton, P., Edwards, P., Mansour, F., Naton, E., Oomen, P.A., Overmeer, W.P.J., Polgar, L., Rieckmann, W., Samsoe-Petersen, L., Staubli, A., Sterk, G., Tavares, K., Tuset, J.J., Viggiani, G., Vivas, A.G., 1988. Results of the fourth joint pesticide testing programme carried out by the IOBC/WPRS- Working Group "Pesticides and Beneficial Organisms". Zeitschrift für Angewandte Entomologie (Journal of Applied Entomology) 105, 321 - 329.

Haynes, R.J., 1988. Sublethal effects of neurotoxic insecticides on insect behavior. Annu. Rev. Entomol. 33, 149-168.

Hood, G.M., 2010. PopTools version 3.2.3. http://www.poptools.org. [accessed 27 October 2015].

Hoyt, S.C., 1969. Integrated chemical control of insects and biological control of mites on apple in Washington. J. Econ. Entomol. 62, 74-86.

Macfadyen, S., Banks, J.E., Stark, J.D., Davies, A.P., 2014. Using semifield studies to examine the effects of pesticides on mobile terrestrial invertebrates. Annu. Rev. Entomol. 59, 383404.

Mills, N.J., Beers, E.H., Shearer, P.W., Unruh, T.R., Amarasekare, K.G., 2016. Comparative analysis of pesticide effects on natural enemies in western orchards: a synthesis of laboratory bioassay data. Biol. Control (this issue).

Pickett, A.D., McPhee, A.W., 1965. Twenty years' experience with integrated control progammes in Nova Scotia apple and pear orchards., Proceedings of the 12th International Congress of Entomology, London, England, pp. 597.

Raudonis, L., Survilienè, E., Valiuškaitè, A., 2004. Toxicity of pesticides to predatory mites and insects in apple-tree site under field conditions. Environmental Toxicology 19, 291-295. 
Ravensburg, W.J., 1981. The natural enemies of the woolly apple aphid Eriosoma lanigerum (Hausm.) (Homoptera: Aphididae), and their susceptibility to diflubenzuron. Meded. Fac. Landbouww. Rijksuniv. 46, 437-441.

Rodrigues, J.R., Mrianda, N.R.C., Rosas, J.D.F., Maciel, C.M., Torres, L.M., 2002. Side-effects of fifteen insecticides on predatory mites (Acari: Phytoseiidae) in apple orchards. IOBC WPRS Bulletin 25, 53-61.

Rosenberg, M.S., Adams, D.C., Gurevitch, J., 1999. MetaWin: Statistical Software for MetaAnalysis. Version 2.0. . Sinauer Associates, Sunderland, Massachusetts.

Ruppel, R.F., 1983. Cumulative insect-days as an index of crop protection. J. Econ. Entomol. 76, $375-377$.

Sauphanor, B., 1993. Side effects of diflubenzuron on a pear psylla predator: Forficula auricularia. Entomophaga 38, 163-174.

Shearer, P.W., Amarasekare, K.G., Mills, N.J., Castagnoli, S., Beers, E.H., Jones, V.P., 2016. Large-plot field studies to assess impacts of newer insecticides on non-target arthropods in Western orchards. Biol. Control (this issue).

Stark, J.D., Banks, J.E., 2003. Population-level effects of pesticides and other toxicants on arthropods. Annu. Rev. Entomol. 48, 505-519.

Stark, J.D., Vargas, R.I., Banks, J.E., 2007. Incorporating ecologically relevant measures of pesticide effect for estimating the compatibility of pesticides and biocontrol agents. J. Econ. Entomol. 100, 1027-1032.

Sterk, G., Hassan, S.A., Baillod, M., Bakker, F., Bigler, F., Blumel, S., Bogenschutz, H., Boller, E.F., Bromand, B., Brun, J., Calis, J.N.M., Coremans-Pelseneer, J., Duso, C., Garrido, S.A., Grove, A., Heimbach, U., Hokkanen, H., Jacas, J.A., Lewis, G., Moreth, L., Polgar, 
L., Roversti, L., Samsoe-Petersen, L., Sauphanor, B., Schaub, L., Staubli, A., Tuset, J.J., Vainio, A., van de Veire, M., Viggiani, G., Vinuela, E., Vogt, H., 1999. Results of the seventh joint pesticide testing programme carried out by the IOBC/WPRS-Working Group 'Pesticides and Beneficial Organisms'. Biocontrol 44, 99-117.

Stern, V.M., Smith, R.F., van den Bosch, R., Hagen, K.S., 1959. The integrated control concept. Hilgardia 29, 81-101.

Thomson, L.J., Hoffman, A.A., 2006. Field validation of laboratory-derived IOBC toxicity ratings for natural enemies in commercial vineyards. Biol. Control 39, 507-515.

Tillman, P.G., Mulrooney, J.E., 2000. Effect of selected insecticides on the natural enemies Coleomegilla maculata and Hippodamia convergens (Coleoptera: Coccellidae), Geocoris punctipes (Hemiptera: Lygaeidae), and Bracon mellitor, Cardiochiles nigriceps, and Cotesia marginiventris (Hymenoptera: Braconidae) in cotton. J. Econ. Entomol. 93, 1638-1643.

Unruh, T.R., Horton, D., Hilton, R., Riedl, H., Beers, E.H., Mills, N., 2006. Effects of new insecticides on natural enemies: acute toxicity and sublethal effects. http://jenny.tfrec.wsu.edu/wtfrc/PDFfinalReports/2006FinalReports/AppleEntomology/U nruhPesticideNE.pdf.

Vogt, H., Just, J., Grutzmacher, A., 2010. Impact of four insecticides on the European earwig, Forficua auricularia L., in an apple orchard. IOBC WPRS Bulletin 54, 112-116.

Wearing, C.H., Attfield, B.A., Colhoun, K., 2010. Biological control of woolly apple aphid, Eriosoma lanigerum (Hausmann), during transition to integrated fruit production for pipfruit in Central Otago, New Zealand. New Zealand Journal of Crop and Horticultural Science 38, 255-273. 
Wennergren, U., Stark, J., 2000. Modeling long-term effects of pesticides on populations:

Beyond just counting dead animals. Ecol. Appl. 10, 295-302. 


\section{Table 1}

Pesticides used in field experiments

laboratory bioassays

$\begin{array}{lll}\text { Apple }^{\mathrm{a}} \quad \text { Pear } & \text { Walnut }\end{array}$

Chlorantraniliprole

X X $\quad$ X

Cyantraniliprole

Spinetoram

Lambda-cyhalothrin

$--\quad X$

$\mathrm{X}$

X --

Novaluron

X

X

$\mathrm{X}$

Sulfur

Mancozeb+copper

${ }^{a}$ Azinphosmethyl was also used as a treatment (1 exp).

${ }^{\mathrm{b}}$ As a pre-mix material, lambda-cyhalothrin+chlorantraniliprole (Voliam Xpress, Syngenta) 
Table 2

Sample type

\begin{tabular}{|c|c|c|c|c|c|c|c|c|}
\hline & & & & & & & \\
\hline Functional group & Taxon & $\begin{array}{l}\text { timed } \\
\text { count }\end{array}$ & $\begin{array}{c}\text { leaf } \\
\text { brush }\end{array}$ & $\begin{array}{l}\text { leaf } \\
\text { scan }\end{array}$ & $\begin{array}{l}\text { sticky } \\
\text { card }\end{array}$ & $\begin{array}{l}\mathrm{PV} \\
\text { trap }\end{array}$ & $\begin{array}{l}\text { tap } \\
\text { count }\end{array}$ & $\begin{array}{c}\text { cardboard } \\
\text { trap }\end{array}$ \\
\hline \multirow[t]{7}{*}{ Secondary pests } & E. lanigerum & A & --- & --- & --- & --- & --- & --- \\
\hline & A. pomi & A & --- & --- & --- & --- & --- & --- \\
\hline & D. plantaginea & A & --- & --- & --- & --- & --- & --- \\
\hline & P. ulmi & --- & $\mathrm{A}, \mathrm{W}$ & --- & --- & --- & --- & --- \\
\hline & T. urticae & --- & $\mathrm{A}, \mathrm{W}$ & --- & --- & --- & --- & --- \\
\hline & C. juglandicola & --- & --- & $\mathrm{W}$ & --- & --- & --- & --- \\
\hline & C. pyricola & --- & --- & $\mathrm{P}$ & --- & --- & --- & --- \\
\hline \multirow{8}{*}{$\begin{array}{l}\text { Natural enemies } \\
\text { (mobile) }\end{array}$} & A. mali & --- & --- & --- & A & --- & --- & --- \\
\hline & T. pallidus & --- & --- & --- & --- & $\mathrm{W}$ & --- & --- \\
\hline & Trechnites sp. & --- & --- & --- & --- & --- & $\mathrm{P}$ & \\
\hline & Parasitic Hymenoptera & --- & --- & --- & --- & $\mathrm{P}, \mathrm{W}$ & A & $\mathrm{A}, \mathrm{P}$ \\
\hline & Predatory Syrphidae & --- & --- & --- & --- & $\mathrm{A}, \mathrm{P}, \mathrm{W}$ & --- & --- \\
\hline & Predatory Neuroptera & --- & --- & --- & --- & $\mathrm{A}, \mathrm{P}, \mathrm{W}$ & --- & --- \\
\hline & Coccinellidae & --- & --- & --- & --- & A & --- & --- \\
\hline & Predatory Heteroptera & --- & --- & --- & --- & --- & $\mathrm{A}, \mathrm{P}$ & --- \\
\hline
\end{tabular}




\begin{tabular}{|c|c|c|c|c|c|c|c|c|}
\hline Natural enemies & Phytoseiidae & --- & $\mathrm{A}, \mathrm{W}$ & --- & --- & --- & --- & --- \\
\hline \multirow[t]{2}{*}{ (resident) } & F. auricularia & --- & --- & --- & --- & --- & --- & $\mathrm{A}, \mathrm{P}$ \\
\hline & Araneae & --- & --- & --- & --- & --- & $\mathrm{A}, \mathrm{P}$ & --- \\
\hline
\end{tabular}


Table 3

\begin{tabular}{lcccc}
\hline & Lab & \multicolumn{3}{c}{ Field studies } \\
\cline { 2 - 5 } Natural enemy group & studies & Apple & Pear & Walnut \\
\hline Phytoseiidae & - & 0 & & 0 \\
F. auricularia & $-*$ & - & 0 & \\
Araneae & - & 0 & + & \\
Hymenoptera & $-*$ & 0 & 0 & - \\
Predatory Syrphidae & $-*$ & + & 0 & 0 \\
Predatory Neuroptera & 0 & 0 & + & 0 \\
A. mali & - & + & & \\
$T$. pallidus & 0 & & & 0 \\
\hline
\end{tabular}

*Laboratory data from IOBC rating system; this organism was not tested in Mills et al., this issue. A minus sign (-) indicates an IOBC Rating of 3-4 (moderately harmful to harmful) for one or more of the experimental treatments.

Empty cells denote that the natural enemy was not sampled in that crop. 

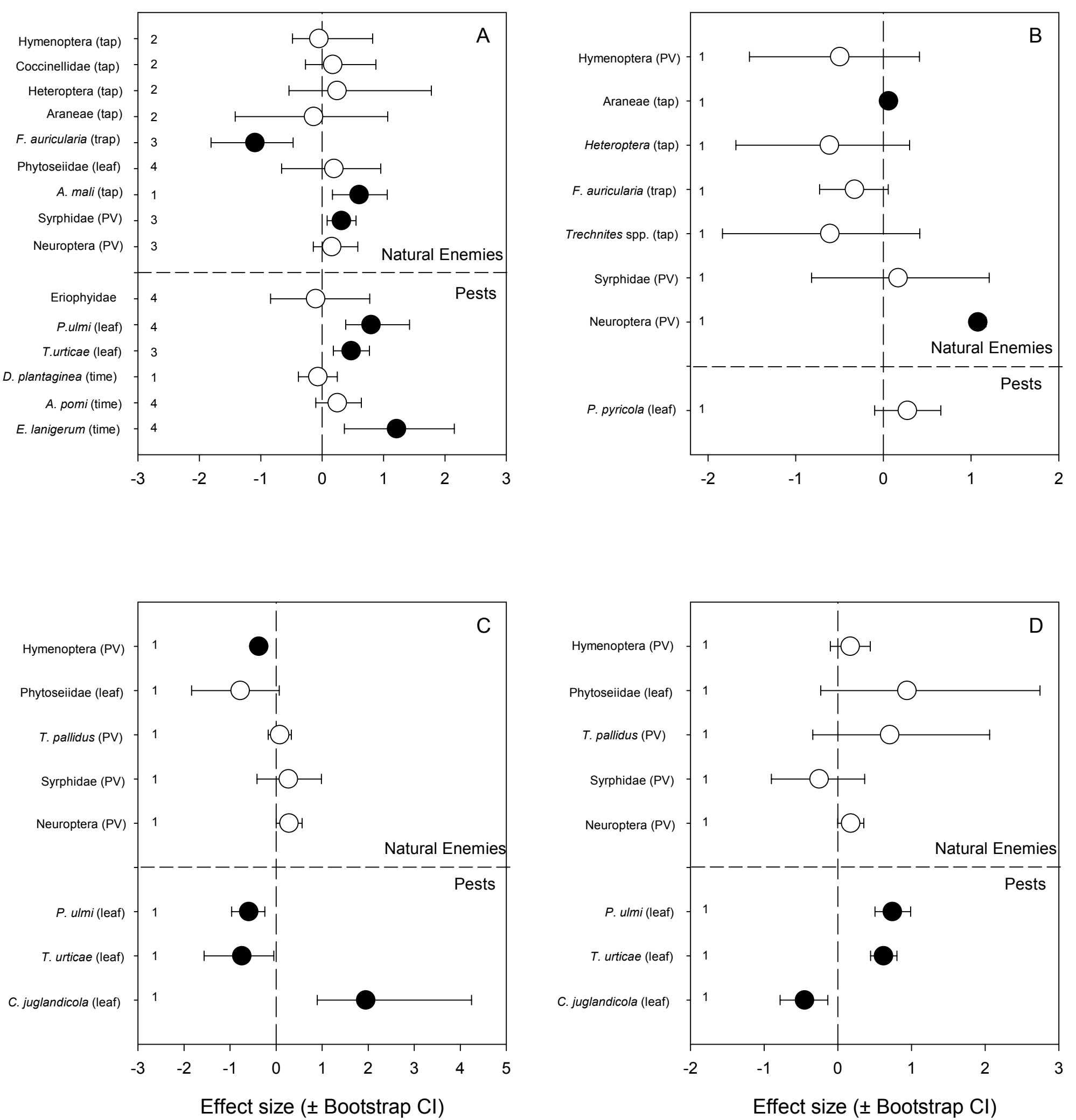

Effect size ( \pm Bootstrap $\mathrm{Cl}$ )

Effect size ( \pm Bootstrap Cl) 
Figure
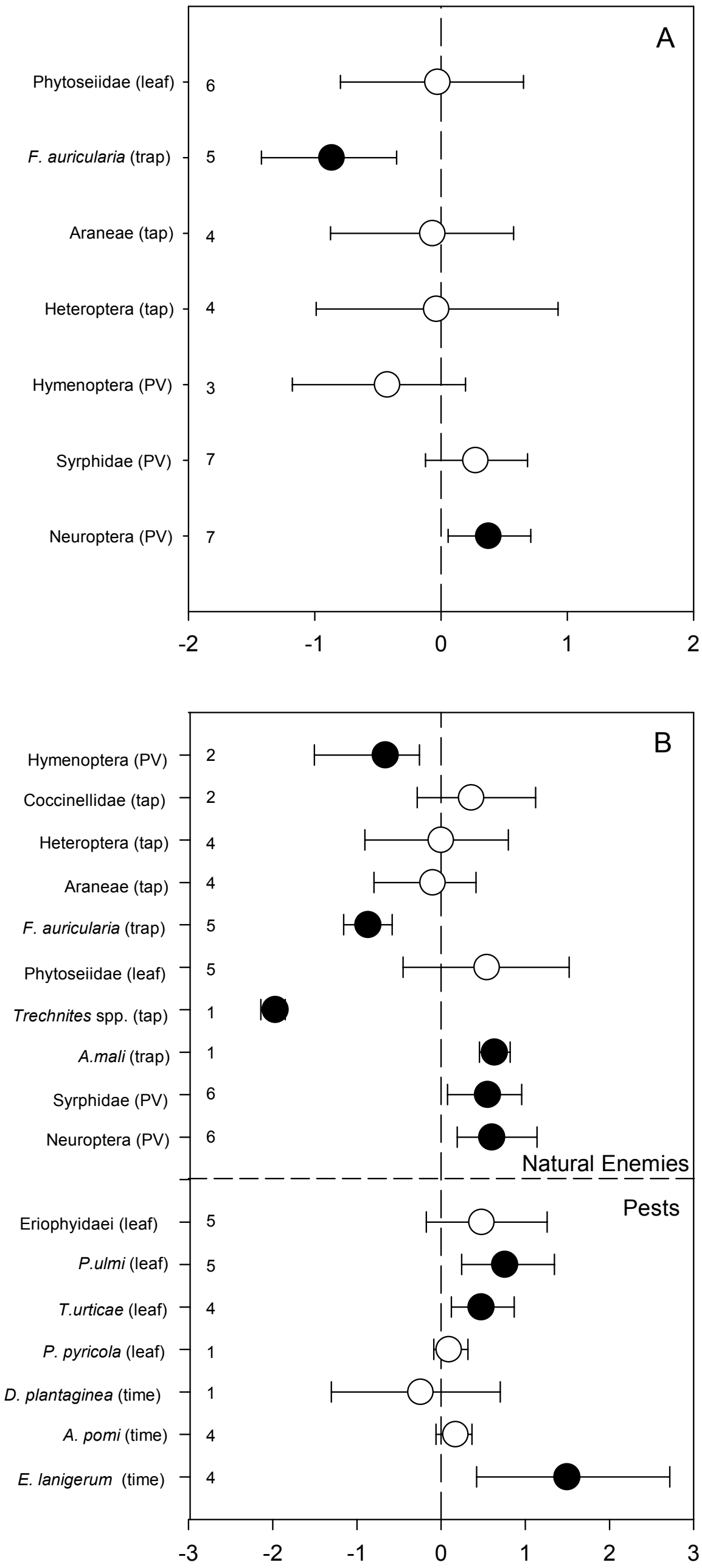

Effect size ( \pm Bootstrap Cl) 

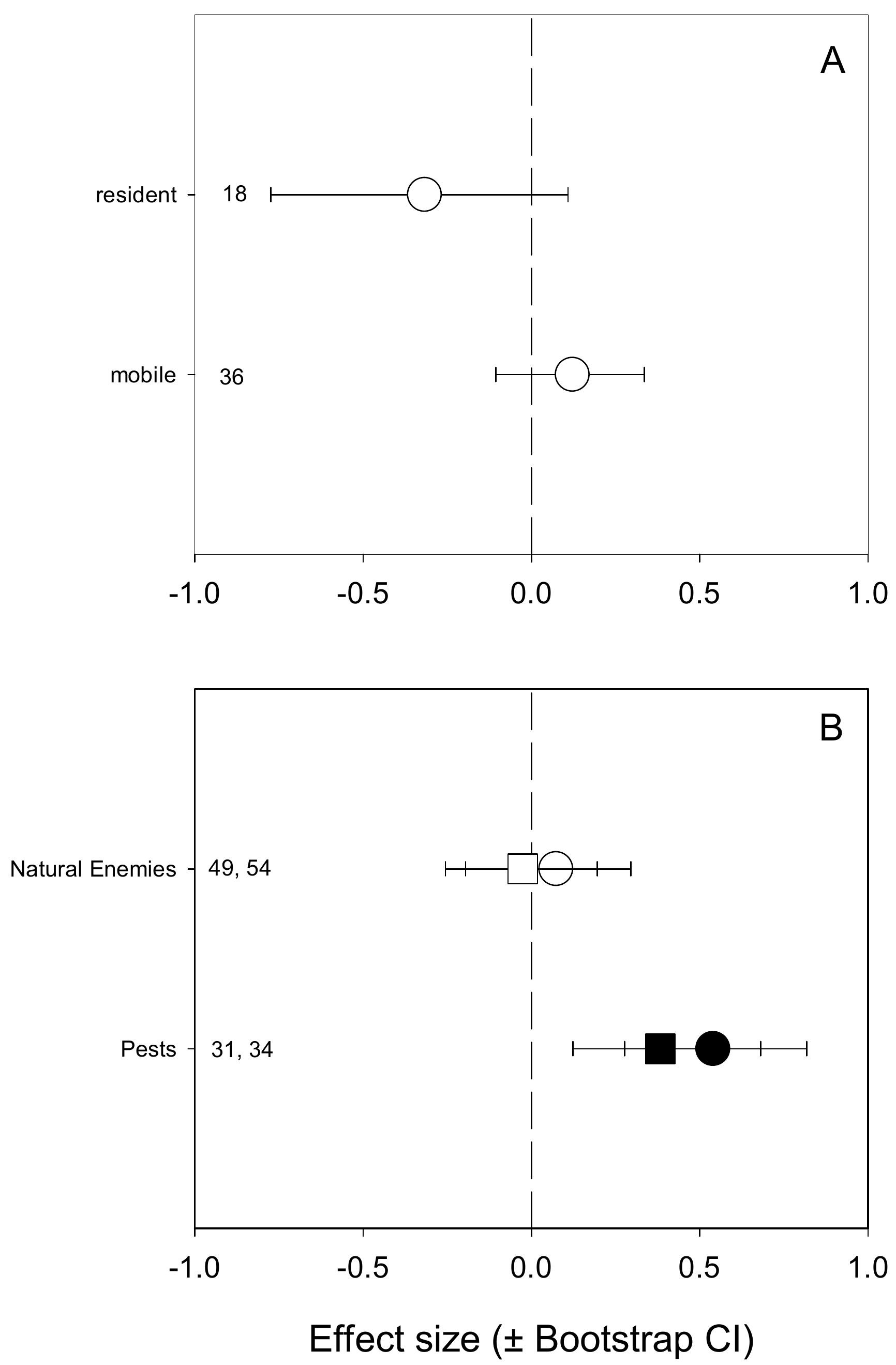

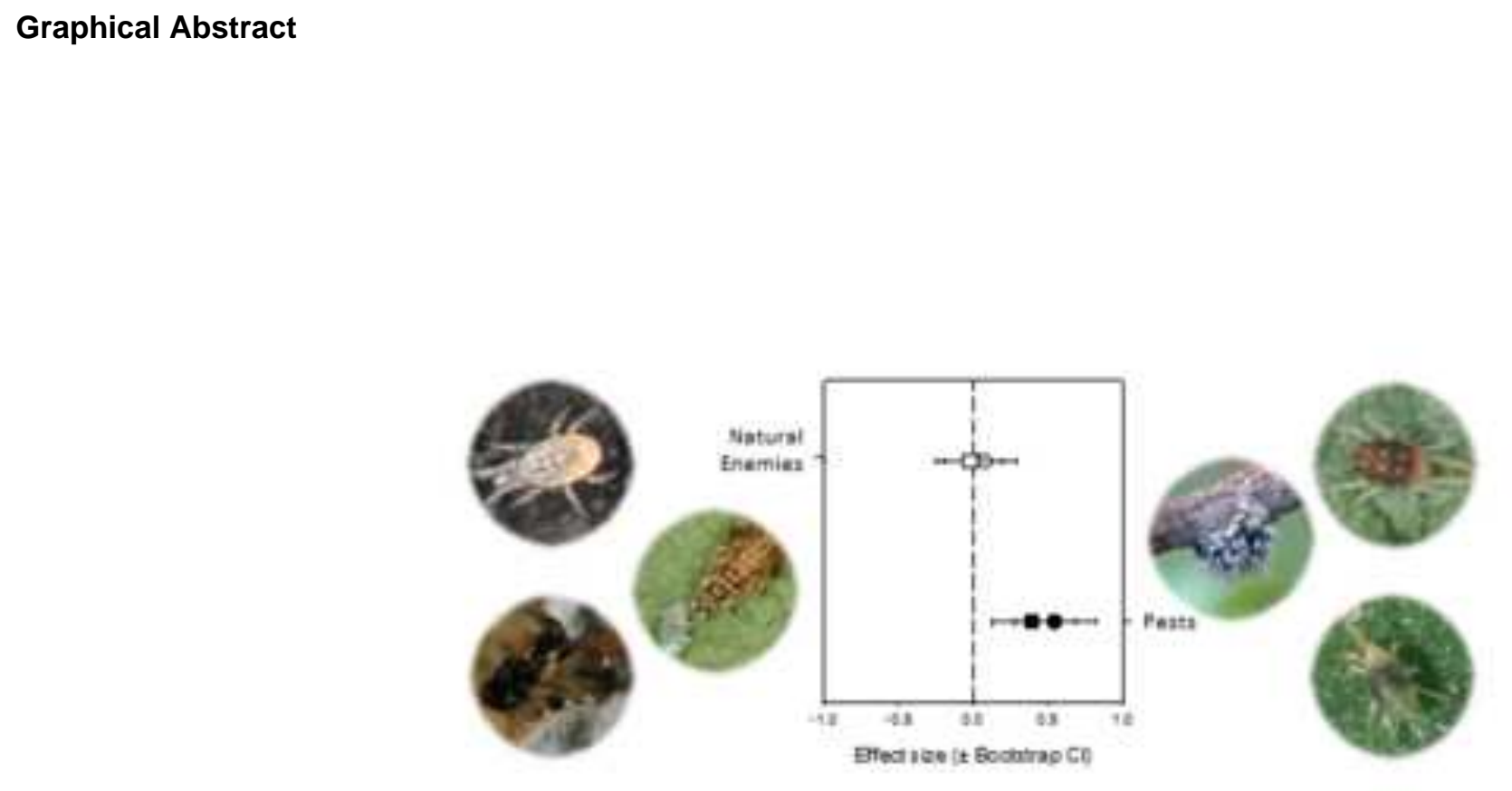

-

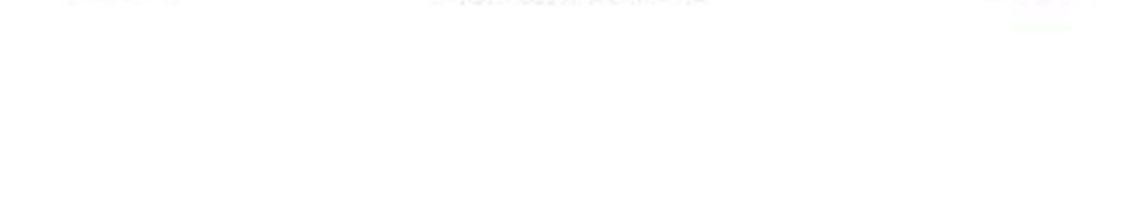

(n)

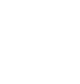
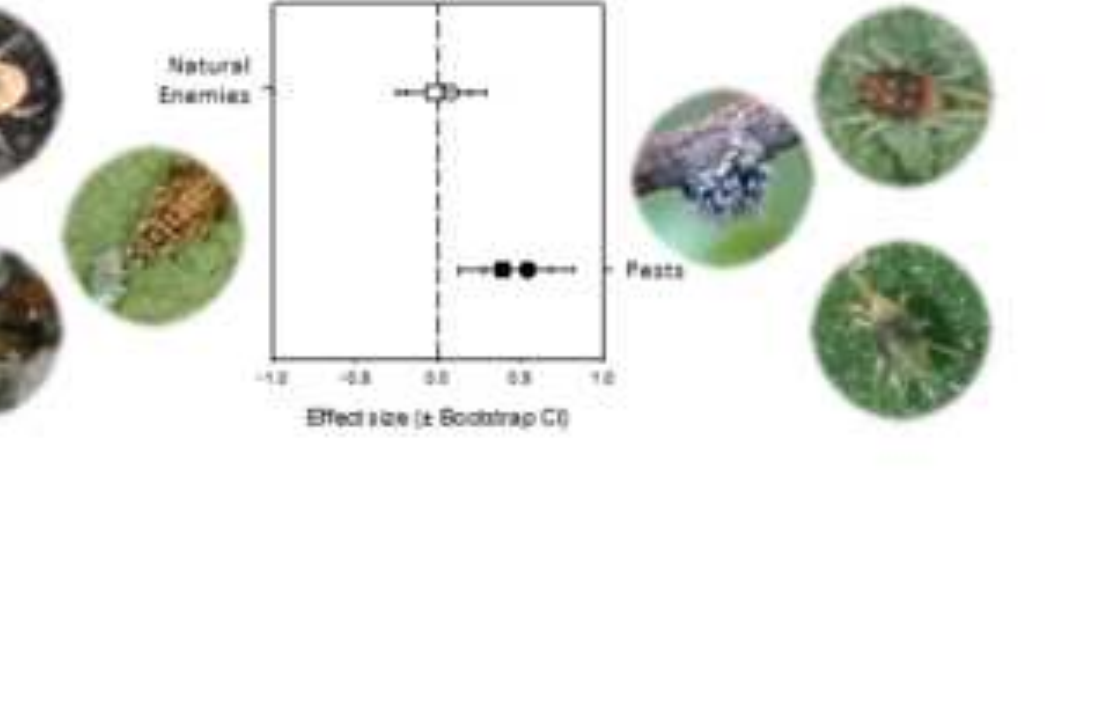